\title{
A Hands-On renewable Energy Based Laboratory for Power Quality Education
}

Session 1333

\author{
Recayi Pecen, Marc A. Timmerman \\ University of Northern Iowa
}

\begin{abstract}
This paper reports design and construction of a testbed for the experimental study of wind/solar "hybrid" power systems for undergraduate power systems engineering technology education. This testbed consists of a small Photovoltaic Solar Array, a DC Wind Turbine/Generator, deep cycle storage batteries, a solid-state DC/AC power inverter, connecting wiring and fuses, $\mathrm{AC}$ and DC circuit breakers, lightning arrester, a wind monitor, a Lab-View based data acquisition system, and supporting instruments. Experimental results are presented depicting power quality issues such as harmonic generation due to the nonlinear loads, and voltage sags due to load switching operations on the $\mathrm{AC}$ side.
\end{abstract}

\section{Introduction}

This paper describes the design, construction, and implementation of a novel testbed for the experimental study of AC/DC integrated power systems. The testbed has been motivated by the problems associated with connecting renewable eco-friendly power sources such as wind turbines and photo-voltaic solar cells to commercial power grids. The complex interactions among the electrical power grid, these generating elements, and other components in the system such as storage batteries and DC to AC power inverters can lead to power quality problems and even grid stability problems. Although wind and solar power sources represent a robust and well-known technology, these stability and power quality issues have limited the deployment of these eco-friendly power sources in commercial power grids. The testbed has been constructed at the Industrial Technology Center at the University of Northern Iowa. Figure 1 illustrates the power inverter unit. Figure 2 illustrates the Photovoltaic solar cells. Figure 3 illustrates the mast-mounted wind turbine/generator with $12 \mathrm{~V}, 63 \mathrm{~A}$ DC rated output. Also mounted on the turbine's mast is a commercially available Model $05103 \mathrm{~V}$ anemometer which includes wind direction and speed sensor. The overall testbed consists of a 750 Watt mast mounted wind turbine, a 680 Watt ground based solar photovoltaic array, a DC to AC power inverter based on solid-state devices, a lead-acid battery array for power storage, a set of linear and non-linear loads, and connecting cabling and junction boxes. Also available are both stand-alone and PC-based data acquisition equipment for recording voltages, currents, and power factor of the electrical signals in the system and also for measuring power quality data such as harmonic responses and transient power fluctuations. Extensive experimental results are presented (1) illustrating steady state voltages and currents in the system, (2) illustrating power quality problems due to small nonlinear load effects, and (3) showing power quality issues related to the switching effects of a very large load on the system. Also presented is a simulation result based on an extensive detailed model of the system as analyzed on a commercial power 
quality software package called PSCAD/EMTDC. Although the testbed has a small-scaled power capacity, it vividly demonstrates many of the complex interactions found in integrated power systems and has been a useful tool for studying possible solutions to such problems.

\section{Literature Review}

A few representative papers in this area of study would include the work of Sabin and coworkers [16] who have described power quality tools for large scale power grids and Koval [8] and coworkers have done similar work on small scale power grids. Several papers have appeared on control schemes to improve power quality including novel work by Konishi and Nakaoka [7] who have used PWM dc-ac conversion circuits in this application and Michigami and coworkers [10] who have taken a more traditional approach using generator exciting currents. Poisson [15] and coworkers have described the use of a high-speed digital controller using DSP chips for power quality improvement control schemes. Barbosa [1] and Heydt [4] and their many coworkers have described the use of discontinuous controller strategies for power quality improvement. Finally Neris, Vovos, and Giannakopoulos [11] have described an IGBT (Integrated-Base-BipolarTransistor) based regulator that has many similarities to the approach taken in this testbed. In the area of ecologically friendly power generation, Jones [5] has described cogeneration using industrial waste heat as a power generation scheme and its effects on power quality. McNeil and coworkers [9], Oliva and coworkers in [12], and Chowdhury [2] have described the power quality aspects of Solar Photovoltaic power generation. Wind turbine power generation has an extensive and very specialized literature including contributions by Demoulias and Dokopoulos [3] on transient power measurement, Thiringer [18] on harmonic power measurement, and Taylor [17] specifically on practical power quality measurements. Kariniotakis and Stavrakakis [6] have presented simulated studies of the interactions between power grids and wind generation systems. The authors' previous publications in this area have highlighted computer programming [13] and educational [14] aspects of this research.

\section{The Testbed System and Pedagogical Use in an Undergraduate Power Systems Course}

Figure 4 presents a functional block diagram of the system. The solar photovoltaic cells and wind turbine provide dc power to the power inverter. The power inverter either sends this power to charge an array of deep-cycle batteries or converts the power to ac. The ac power is used in a set of linear (light bulbs, heaters) and nonlinear loads (fluorescent bulbs, high-efficiency bulbs) connected to the system via a junction box. Instrumentation resources include hand-held power quality instruments (Figure 1) that can be interfaced to a PC (Figure 5) for data acquisition. Not depicted is a stand-alone PC-based data acquisition card equipped with 32 channels of isolation amplifiers for multi-point measurements. The lower object mounted on a boom in Figure 3 is an anemometer that monitors wind direction and wind speed using this PC-based multi-point measurement system. Figure 6 depicts the junction box for the system. Numerous bus fuses are used for protection of the users of the system. A surge arrestor is also included due to the damage possible from the mastmounted wind turbine by lightning strikes. The testbed is used as a laboratory experiment in the class of 330:038 Introduction to Electrical Power and Machinery (with previous title 330:038 Industrial Electricity). The lab activities include the following aspects: (1) use of wind and solar energy resources in the power generation, (2) AC/DC power system interactions which includes power 
quality issues in both AC and DC sides of the system, (3) computer based monitoring of power and harmonics with variety of linear and nonlinear loads, and (4) fault studies. Students are very pleased to use the testbed unit as long as the weather has sufficient wind and/or sunlight.

\section{Data Examples}

As examples of steady-state data, Figure 7 depicts the battery dc voltage for the no-load (electrical load) situation and Figure 8 depicts the output voltage of the wind turbine/generator for the no load (electrical load) situation. Some examples of transient responses with respect to small loads include Figure 9 which depicts distortion in the DC voltage at the input of the inverter when small combined linear and nonlinear loads are applied to the system. Figure 10 depicts the harmonic spectrum of the distorted ac signal at the output of the inverter. As can be seen, the total harmonic distortion caused by the small nonlinear loads is in the range of 30\%. A major problem of hybrid power generation systems is their sensitivity to nonlinear loads. Figure 11 depicts a major load change situation. This figure is battery voltage when a large load of $8 \mathrm{~A}$ is connected at $5 \mathrm{~s}$ and a load of $9 \mathrm{~A}$ is connected at $54 \mathrm{~s}$. The battery takes almost $30 \mathrm{~s}$ to recover from the voltage sag caused by the large load changes. Figure 12 depicts the major voltage sags at the input of the inverter during repeated switching of the $8 \mathrm{~A}$ load. These data vividly illustrate the problems of interconnecting hybrid systems with commercial power grids. Even small nonlinear loads may cause unacceptable levels of harmonic distortion. The long recovery time of battery-based storage systems can be a major obstacle in the practical implementation of hybrid power systems.

\section{Simulation Examples}

Figure 13 depicts a PSCAD/EMTDC simulation of a nonlinear load situation. The upper graph is a voltage waveform and the lower two graphs are harmonic responses. The availability of this simulation allows for potential tests to be evaluated for possible hazards prior to committing the physical resource of the testbed. Work is continuing on improving this simulation model.

\section{Conclusions}

A testbed for studying the complex interactions between a simple "wind/solar" hybrid power unit and commercial power grid has been developed at the University of Northern Iowa. The testbed consists of a Photovoltaic solar array, a wind turbine/generator, a deep-cycle battery array, an inverter, connecting junctions, and supporting instruments. Several examples of both steady state and transient responses are shown from experimental data. A harmonic response to a small non-linear load is depicted from a computer simulation. Work is progressing on this testbed to monitor all the variables by LabView ${ }^{\mathrm{TM}} 6.0$ and transfer the real-time data to an active web server for easy access. Refinements in the computer model are in progress and a multi-point isolated PC-based data acquisition system is being deployed to enhance the capabilities of the testbed.

VII. Acknowledgements

The authors acknowledge the University of Northern Iowa Graduate School for providing summer fellowship in July 2000 for this research project. 


\section{References}

1. Barbosa, P. G et. al. "Control strategy for grid connected dc ac converters with load power factor correction," IEE Proceedings. Generation, Transmission and Distribution, v. 145 no. 5 Sept. '98 p. 487-91.

2. Chowdhury, B. H., "Designing an innovative laboratory to teach concepts in grid tied renewable and other dispersed resources," ASEE Annual Conference and Exhibition, session no. 3532 June '99.

3. Demoulias, C. S; \& Dokopoulos, P, "Electrical transients of wind turbines in a small power grid," IEEE Transactions on Energy Conversion, v. 11 Sept. '96 p. 636-42.

4. Heydt, G. T; Tan, W; \& LaRose, T, " Simulation and analysis of series voltage boost technology for power quality enhancement," IEEE Transactions on Power Delivery, v. 13 no. 4 Oct. '98 p. 1335-41.

5. Jones, C., "Cogen system meets triple threat of industry turmoil," Power, v. 142 Jan./Feb. '98 p. 48-50.

6. Kariniotakis, G. N; \& Stavrakakis, G. S, "A general simulation algorithm for the accurate assessment of isolated diesel wind turbines systems interaction. Part II: implementation of the algorithm and case studies with induction generators," IEEE Transactions on Energy Conversion, v. 10 Sept. '95 p. 584-90.

7. Konishi, Y.; \& Nakaoka, M., "Current fed three phase converter with optimum PWM scheme and its practical input line filter design," IEE Proc. Elec. Pow., v. 145 no. 6 Nov. '98 p. 535-45.

8. Koval, D. O.; Xu, W.; \& Salmon, P., "Power quality characteristics of rural electric secondary power systems, "IEEE Transactions on Industry Applications, v. 35 no. 2 Mar./Apr. '99 p. 332-8.

9. McNeill, B. W.; \& Mirza, M. A., "Estimated power quality for line commutated photovoltaic residential system," IEEE Transactions on Power Apparatus and Systems, v. 102 Oct. '83 p. 3288-95

10. Michigami, T.; Onizuka, K. A.; \& Kitamura, S., "Development of Advanced Generator Control Regulator (PSVR) for Improving Voltage Stability of Bulk Power Transmission System, " EE Japan, v. 100 B no. 11 Nov. '90, p. 887-94.

11. Neris, A. S; Vovos, N. A; \& Giannakopoulos, G. B, "A variable speed wind energy conversion scheme for connection to weak AC systems," IEEE Transactions on Energy Conversion, v. 14 no. 1 Mar. '99 p. 122-7.

12. Oliva, A. R; Balda, J. C; \& McNabb, D. W, "Power quality monitoring of a PV generator," IEEE Transactions on Energy Conversion, v. 13 no. 2 June '98 p. 188-3.

13. Pecen R.; \& Timmerman M., "A novel power quality scheme to improve a utility interface in a small sized hybrid solar/wind generation unit," 10th. International Power Quality Conference, November '99.

14. Pecen, R.; Salim, Md.; \& M. Timmerman, "A hybrid solar wind power generation system as an instructional resource for industrial technology students," Journal of Industrial Technology, v. 16 3, May '00.

15. Poisson, O; Rioual, P; \& Meunier, M, "New signal processing tools applied to power quality analysis," IEEE Transactions on Power Delivery, v. 14 no. 2 Apr. '99 p. 561-.

16. Sabin, D. D.; Brooks, D.;\& Sundaram, A., "Indices for assessing harmonic distortion from power quality measurements: definitions \& benchmark data," IEEE Trans. on Power Delivery, v. 14 no. 2 Apr. '99 p. 489-6.

17. Taylor, G. J, "Power quality measurements on a $24 \mathrm{~m}$ windmill," IEE Proceedings. Part A, Physical Science, Measurement and Instrumentation, Management and Education, Reviews, v. 134 May '87 p. 435-0.

18. Thiringer, T., "Power quality measurements performed on a low voltage grid equipped with two wind turbines," IEEE Transactions on Energy Conversion, v. 11 Sept. '96 p. 601-6.

\section{RECAYI PECEN}

Recayi Pecen holds a B.S.E.E. and an M.S. in Controls and Computer Engineering from the Istanbul Technical University, an M.S.E.E. from the University of Colorado at Boulder, and a Ph.D. in Electrical Engineering from the University of Wyoming. He has served in the University of Wyoming, and South Dakota State University. He is currently an assistant professor and program coordinator at the University of Northern Iowa. His research interests and publications are in the areas of AC/DC Power System Interactions, power quality, and grid-connected renewable energy applications. http://www.uni.edu/indtech/ems

\section{MARC A. TIMMERMAN}

Marc A. Timmerman holds a B.S.E.E. from the Santa Clara University, a M.Eng.E.E. from the Rensselaer Polytechnic Institute, and a Ph.D. from the George W. Woodruff School of Mechanical Engineering at Georgia Tech. He has served on the faculties of the University of Tulsa, the Louisiana State University at Baton Rouge, and the University of Northern Iowa. His research publications are in the area of embedded microprocessors and DSP, Mechatronics, and vibrations. http://www.uni.edu/indtech/ems 
Figures

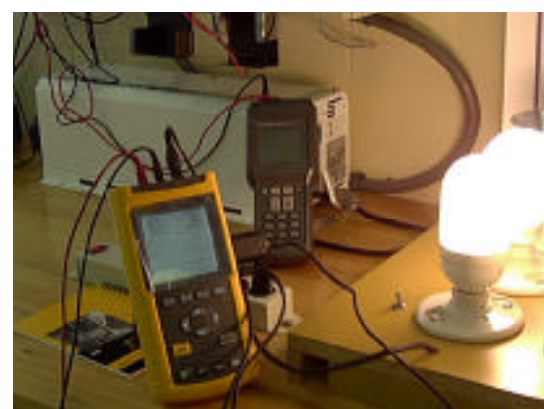

Figure 1. Inverter and AC output unit.

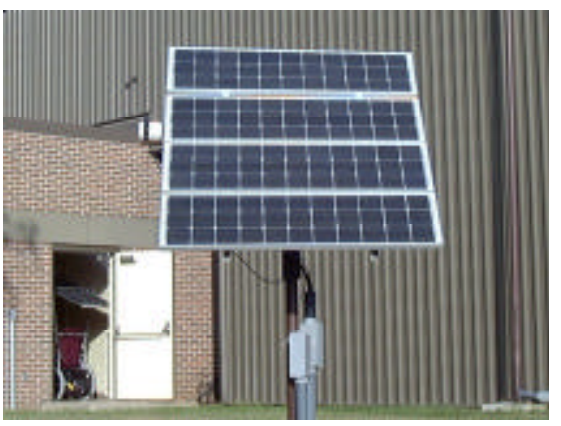

Figure 2. Solar Array assembly.

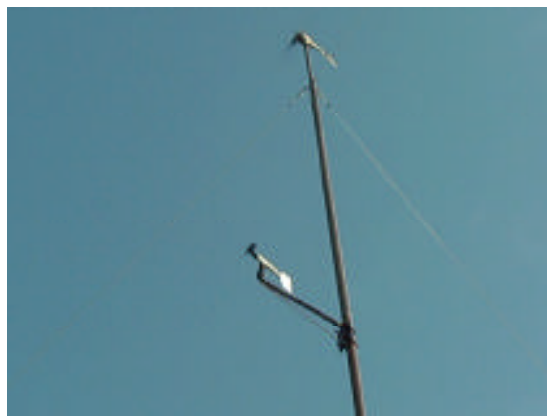

Figure 3. Mast mounted wind generator.

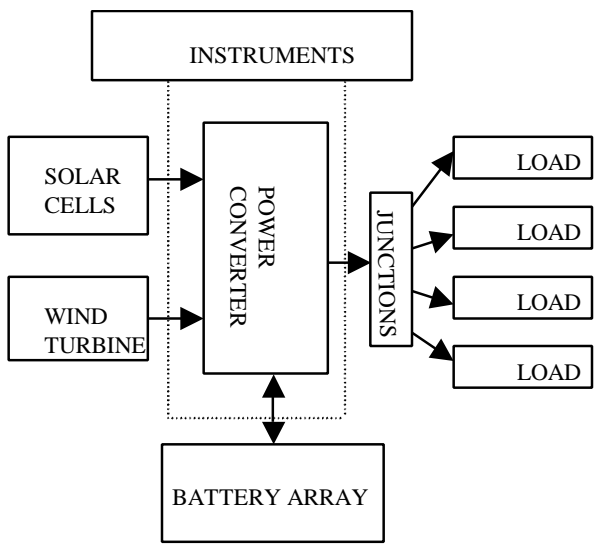

Figure 4. System diagram.

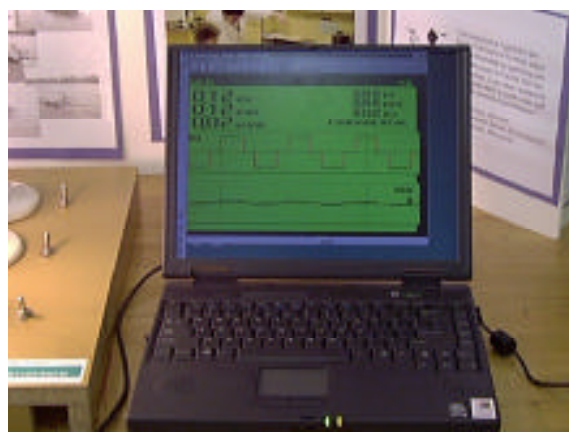

Figure 5. Instrumentation setup.

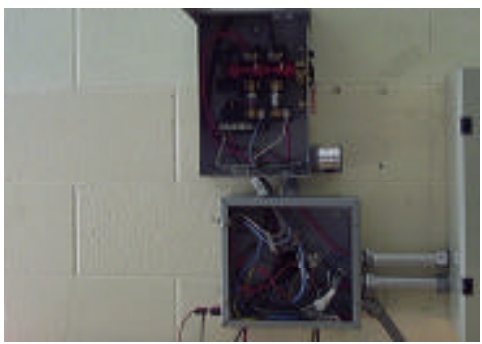

Figure 6. Junction box.

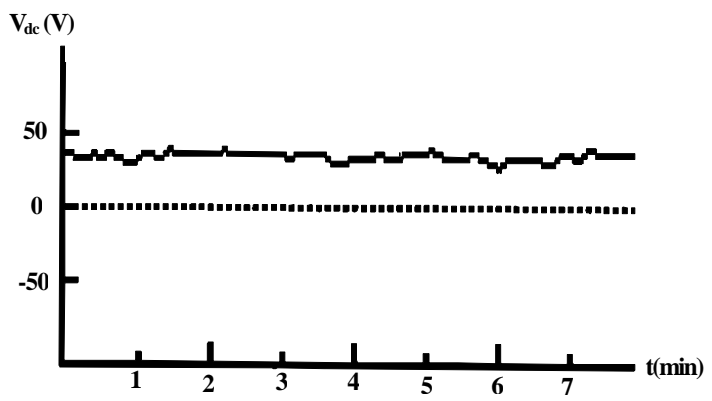

Figure 7. DC voltage measured at battery terminals at variable wind and load changes at $\mathrm{AC}$ side.

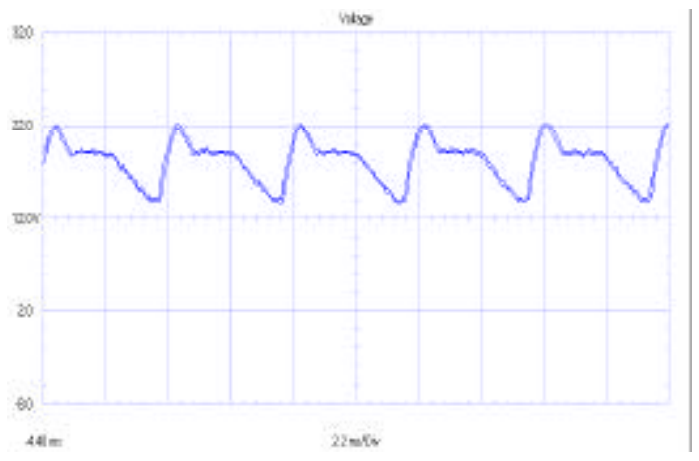

Figure 8. Wind turbine/generator output at no-load.

Proceedings of the 2001 American Society for Engineering Education Annual Conference \& Exposition Copyright ${ }^{\circ}$ 2001, American Society for Engineering Education 


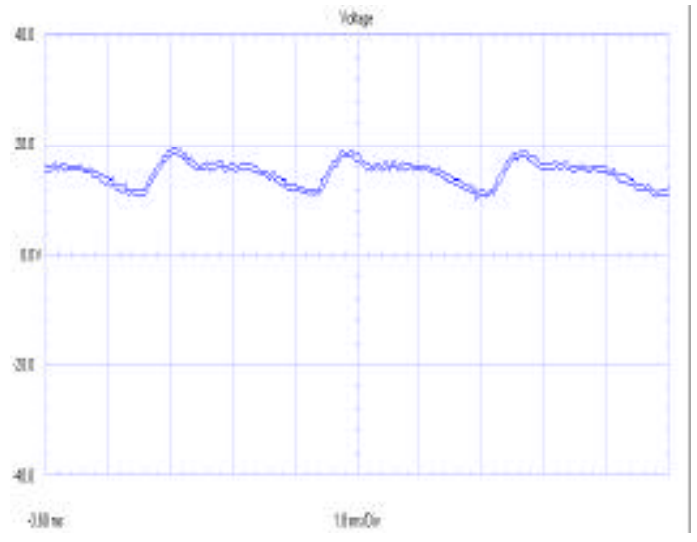

Figure 9. Distorted DC voltage at inverter input.

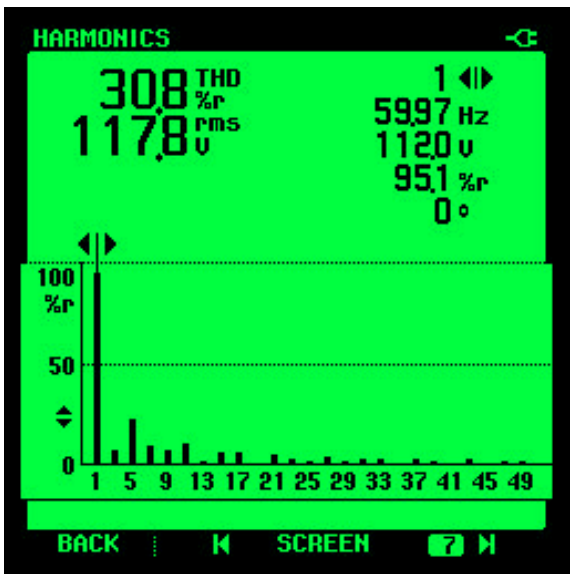

Figure 10. Harmonic spectrum of distorted AC signal

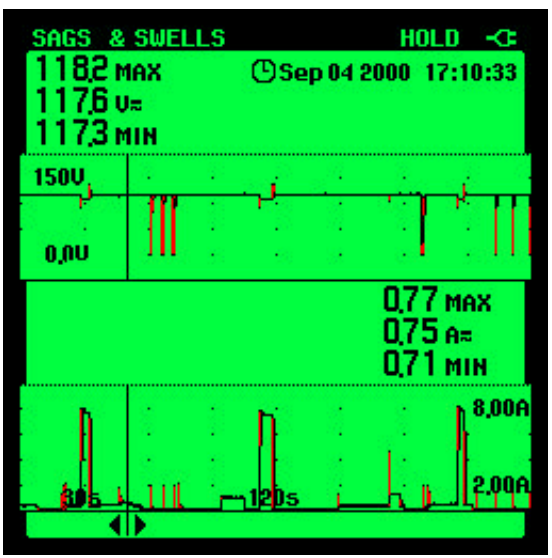

Figure 11. AC Voltage output with a load of $8 \mathrm{~A}$ at $5 \mathrm{~s}$ and $9 \mathrm{~A}$ at $54 \mathrm{~s}$.

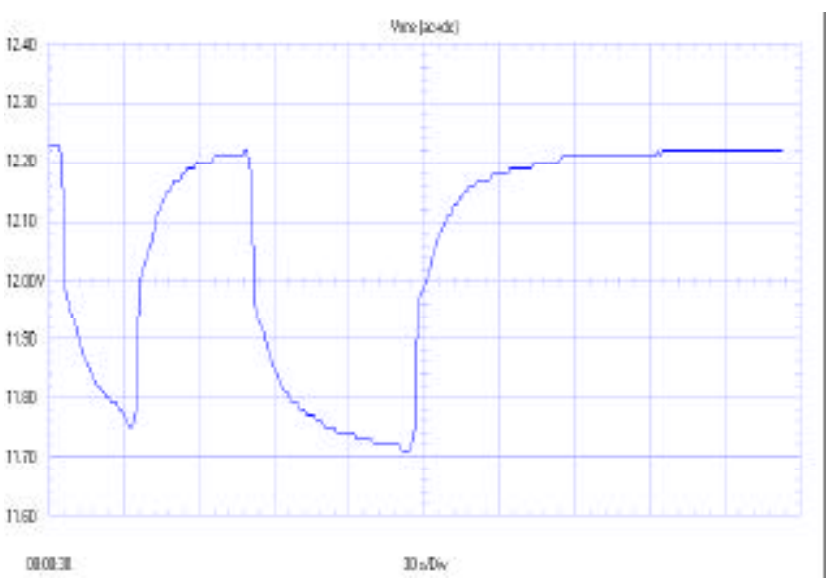

Figure 12. Inverter input voltage sags and swells during repeated 8 A load switching.
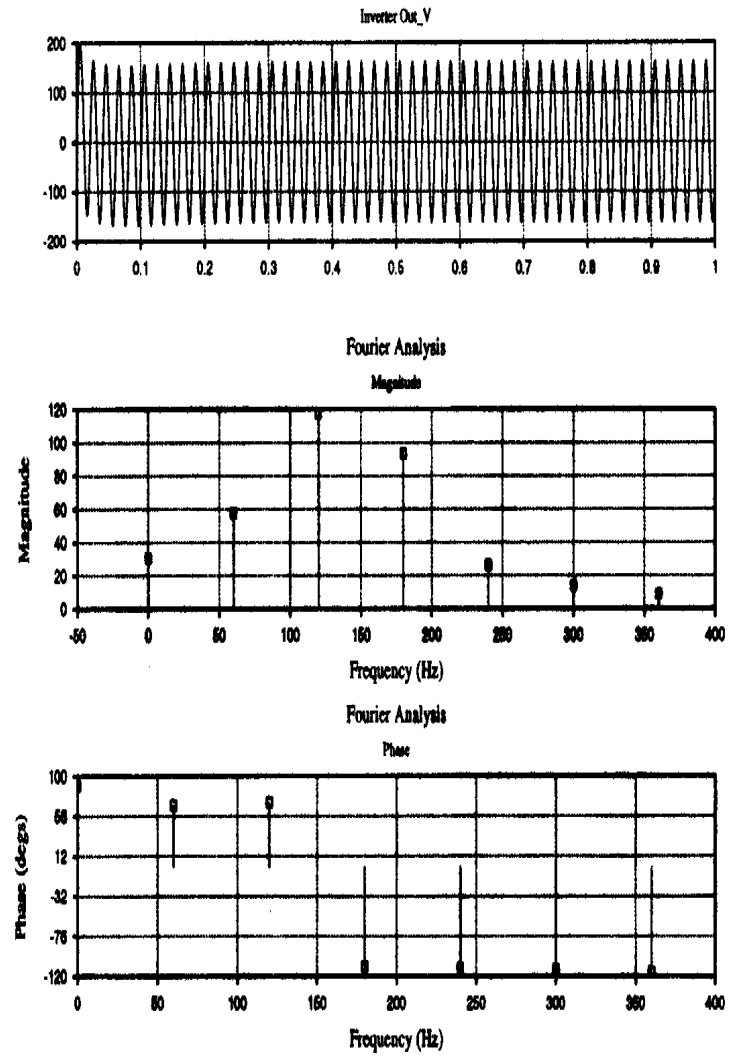

Figure 13. Simulation of harmonic generation. 